\title{
Ensino integrado no ciclo básico
}

Maria Alice Sigaud Lent*

\section{RESUMO}

O artigo discute a atuação do Núcleo de Tecnologia Educacional para a Saúde (NUTES) e do Centro Latino Americano de Tecnologia Educacional para a Saúde (CLATES) junto aos docentes do Instituto de Ciências Biomédicas (ICB) da Universidade Federal do Rio de Janeiro (UFRJ). Descreve a metodologia utilizada nos cursos do ICB, assim como as mudanças curriculares propostas, e salienta a importância da integração das disciplinas do ciclo básico, como um fator facilitador no processo de ensino-aprendizagem. Aponta, também, a importância do treinamento didático dos docentes, a fim de que possam aprimorar o planejamento de seus cursos e desenvolver atitude mais positiva em relação ao ensino.

\section{A CRIAC̣ĀO DO NUTES/CLATES}

Em 1973 foi criado, no Centro de Ciências da Saúde da UFRJ, o Núcleo de Tecnologia Educacional para a Saúde, com os objetivos de preparar docentes do setor saúde para o uso de nova metodologia educacional e de assessorar os professores no planejamento didático de suas disciplinas. Nesse mesmo ano, a Organização PanAmericana da Saúde (OPAS) criou, junto ao NUTES, o Centro Latino Americano de Tecnologia Educacional para a Saúde. A partir de então, a instituição ficou conhecida como NUTES/CLATES.

A atuação do NUTES/CLATES no Centro de Ciências da Saúde se deu através de cursos intensivos de 40 horas, nos quais se discutia nova metodologia para o ensino na área da saúde.
Estes cursos serviram como motivação inicial para os docentes no sentido de reformularem os seus cursos, assim como de entenderem melhor os conceitos educacionais. Em geral, a maioria de nossos docentes alcança a posição de professor universitário pelos seus méritos acadêmicos e poucos recebem treinamento didático. A enorme receptividade aos cursos do NUTES/CLATES se fez sentir loyo nos primeiros anos. Em 1973 e 1974, foram realizados nove cursos de Didática Aplicada ao Ensino Superior com a participação de duzentos e vinte docentes da área da saúde, sendo que cinqüenta por cento pertenciam à UFRJ.

À medida que a equipe do NUTES/CLATES crescia, o escopo de sua atuação frente ao ICB tornava-se mais abrangente, sendo então implementadas as assessorias didáticas com o objetivo de favorecer as mudanças discutidas em relação aos cursos de treinamento.

\section{COMO FORAM ORIENTADOS OS CURSOS DO CICLO BĀSICO}

Os primeiros cursos assessorados no ciclo básico, em 1974, foram os de Fisiologia Cardiorrespiratória, Neurofisiologia e Fisiologia Endócrina. As assessorias funcionaram regularmente, através de encontros semanais com os docentes, quando a equipe do NUTES/CLATES procurava levar os professores a discutir os conceitos que deveriam embasar o planejamento da disciplina.

Nesse período, foi implantada a avaliação formativa mediante o uso de computador, e se iniciou a utilização de meios audiovisuais para o ensino de determinados programas. No final de 1974, no entanto, estava claro para a equipe do

* Professora Assistente do Núcleo de Tecnologia Educacional para a Saúde da Universidade Federal do Rio de Janeiro. 
NUTES/CLATES, e para os docentes do ICB, que as mudanças no planejamento das disciplinas, somente em nível metodológico, não eram suficientes para trazer modificações substanciais no processo de ensino-aprendizagem. Partiu-se, então, para uma tentativa de mudança curricular.

\section{DISCIPLINA INTEGRADA}

Em 1975, os professores efetuaram uma proposta de mudança curricular. Para isto se reuniram e propuseram num documento que o ensino no ciclo básico, ao invés de continuar ministrando disciplinas isoladas (Anatomia, $\mathrm{Fi}$ siologia, Histologia), deveria ser desenvolvido a partir de disciplinas integradas (Sistema nervoso,
Sistema cardiorrespiratório e Sistema endócrino). Isto significava um trabalho de aproximação das disciplinas e o desenvolvimento de novos planejamentos dos cursos. De acordo com a proposta, cada bloco de estudos seria formado pela integração de setores afins das várias disciplinas lecionadas pelos Departamentos do ICB, Instituto de Biofísica, Instituto de Microbiologia, bem como de alguns Departamentos da Faculdade de Medicina e dos Institutos de Biologia e Nutrição. $O$ ensino seria ministrado por professores destes vários Departamentos, reunidos por uma coordenação única.

O Quadro I mostra a organização proposta para os Blocos Integrados que se destinam ao ensino do primeiro ciclo do Curso Médico.

\section{QUADRO 1}

BLOCOS INTEGRADOS PARA O PRIMEIRO CICLO DO CURSO MÉDICO

\begin{tabular}{|c|c|}
\hline Bloco & Conteúdo \\
\hline 1. Organização morfofuncional do corpo humano & $\begin{array}{l}\text { Estudo morfofuncional das células e tecidos. Organização } \\
\text { funcional dos grandes sistemas. }\end{array}$ \\
\hline 2. Biologia geral do homem & $\begin{array}{l}\text { O fenômeno humano. Crescimento e reprodução. Envelhe- } \\
\text { cimento e morte. Comunidade. Saúde, doença, prevenção } \\
\text { e tratamento. }\end{array}$ \\
\hline 3. Funções celulares & $\begin{array}{l}\text { Metabolismo intermediário e trocas energéticas. Enzimas. } \\
\text { Síntese de proteínas. Digestão e secreção. }\end{array}$ \\
\hline 4. Sistema locomotor e tegumentar & $\begin{array}{l}\text { Estudo morfofuncional do esqueleto e músculo esqueléti- } \\
\text { cos. Esquema geral de controle motor dos músculos. }\end{array}$ \\
\hline 5. Sistema nervoso & $\begin{array}{l}\text { Organização morfofuncional do sistema nervoso. Suas fun- } \\
\text { ções de controle na vida de relação e na vida vegetativa. }\end{array}$ \\
\hline 6. Sistema circulatório e respiratório & $\begin{array}{l}\text { Organização morfofuncional dos sistemas cardiovascular e } \\
\text { respiratório. Funções, desempenho e controle de circula- } \\
\text { ção e respiração. }\end{array}$ \\
\hline 7. Sistema urinário e equilíbrio hidrossalino & $\begin{array}{l}\text { Organização morfofuncional do rim. Funções do rim e sua } \\
\text { regulação. Conceito de meio interno e homeostase. Equili- } \\
\text { brio hidrossalino. Equilıbrio ácido-base. }\end{array}$ \\
\hline 8. Digestão, nutrição e metabolismo & $\begin{array}{l}\text { Estudo morfofuncional do aparelho digestivo. Suas fun- } \\
\text { ções, desempenho e controle. Metabolismo. Nutrição. }\end{array}$ \\
\hline 9. Sistema endócrino, reprodução e crescimento & $\begin{array}{l}\text { Estudo morfofuncional das glândulas endócrinas. Secreção } \\
\text { hormonal. Sistema endócrino como sistema de controle in- } \\
\text { tegrativo. Controle endócrino e estudo funcional de repro- } \\
\text { dução e do crescimento. }\end{array}$ \\
\hline 10. Sangue e sistema hematopoiético & $\begin{array}{l}\text { Estudo químico do plasma. Taxa de rotatividade e meca- } \\
\text { nismo de renovação do plasma e elementos figurados. He- } \\
\text { matopoiese e seu controle. Linfa. }\end{array}$ \\
\hline 11. Sistema tegumentar & $\begin{array}{l}\text { Estudo morfofuncional da pele e anexos. Funções da pele } \\
\text { e sua regulação. }\end{array}$ \\
\hline 12. Agressão e defesa & $\begin{array}{l}\text { Agressões físicas, químicas e biológicas ao organismo. Ra- } \\
\text { diobiologia, Microbiologia e Parasitologia. Reciclagem am- } \\
\text { biental dos agentes patogênicos biológicos e químicos. Ca- } \\
\text { pacidade de defesa do organismo. }\end{array}$ \\
\hline
\end{tabular}


O NUTES/CLATES colaborou para a implantação deste novo currículo, assessorando os professores no processo de planejamento e implementação de alguns dos blocos integrados.

Embora do ponto de vista teórico a idéia da integração parecesse muito interessante, uma vez que fornecia ao aluno um conhecimento mais harmonioso e integral do organismo, na prática as dificuldades se acumularam. O primeiro impasse referiu-se à falta de contato entre os docentes das diferentes disciplinas. Não era fácil conseguir que docentes de Anatomia, Histologia e Fisiologia planejassem uma unidade de uma disciplina integrada.

Surgiram conflitos relativos a conceitos, metodologia e maneira de trabalhar com o aluno. A departamentalização contribuiu bastante para o isolamento entre os docentes, dificultando também o entrosamento no trabalho. Como resultado desta dificuldade, os cursos planejados nem sempre eram harmoniosos e muitas vezes ocorria o domínio de uma disciplina sobre outra. Apesar das dificuldades, do ponto de vista dos docentes houve uma boa oportunidade de reflexão sobre as especificidades de sua disciplina, e também uma boa ocasião para uma mudança de atitude no sentido da supervalorização de seu programa, em detrimento de outros.

Ao final de 1978, já havia blocos integrados em funcionamento, tais como: Sistema Nervoso, Sistema Cardiorrespiratório, Sistema Digestivo e Urinário e, em 1979, o de Sistema EndócrinoReprodutor. Neste mesmo ano, o Diretor da Faculdade de Medicina criou a Comissão Permanente de Assessoramento Operacional do Conselho de Curso da Faculdade de Medicina, presidida pelo Professor Clementino Fraga, que analisou o projeto de currículo proposto em 1975 e tornou viável o novo currículo, apresentando o Anteprojeto da Organização Curricular para o Curso Médico da UFRJ (ver Quadro 2).

Criou-se também, junto ao ICB, uma Comissão de Blocos Integrados, presidida pelo Professor Carlos Eduardo Rocha Miranda, que ficou encarregada de estudar sua implementação e de nomear os coordenadores de cada bloco.

\section{METODOLOGIA DESENVOLVIDA NO PLANEJAMENTO DAS DISCIPLINAS INTEGRADAS}

O primeiro passo na assessoria didática era levar o professor a pensar sobre as funções do profissional que ele iria formar. Esta reflexão era
QUADRO 2

\section{ORGANIZAÇÃO CURRICULAR DO CURSO} MÉDICO DA UFRJ

\begin{tabular}{|c|c|}
\hline Período & Disciplina Integrada \\
\hline 10 & $\begin{array}{l}\text { Anatomia Geral } \\
\text { Histologia Fundamental } \\
\text { Biofísica Fundamental } \\
\text { Bioquímica Fundamental } \\
\text { Biologia Celular }\end{array}$ \\
\hline $2 \circ$ & $\begin{array}{l}\text { Sistema Locomotor } \\
\text { Sistema Nervoso } \\
\text { Sistema Cardiovascular e Respiratório } \\
\text { Sistema Hemolinfopoiético }\end{array}$ \\
\hline 30 & $\begin{array}{l}\text { Sistema Urinário } \\
\text { Sistema Digestivo } \\
\text { Sistema Endócrino e Reprodução }\end{array}$ \\
\hline 40 & $\begin{array}{l}\text { Introdução à Medicina Clínica I } \\
\text { Mecanismos Básicos de Saúde e Doença }\end{array}$ \\
\hline 50 & $\begin{array}{l}\text { Introdução à Medicina Clínica II } \\
\text { Saúde Coletiva I }\end{array}$ \\
\hline $6^{\circ}$ & $\begin{array}{l}\text { Medicina Clínica I } \\
\text { Saúde Coletiva II } \\
\text { Bases da Cirurgia e da Anestesiologia }\end{array}$ \\
\hline 70 & $\begin{array}{l}\text { Medicina Clínica II } \\
\text { Psiquiatria e Saúde Mental } \\
\text { Medicina Legal e Deontologia }\end{array}$ \\
\hline 80 & $\begin{array}{l}\text { Medicina Clínica III } \\
\text { Obstetrícia e Ginecologia } \\
\text { Puericultura }\end{array}$ \\
\hline بִ & $\begin{array}{l}\text { Medicina Clínica IV } \\
\text { Traumatologia }\end{array}$ \\
\hline $10,11,120$ & Internato \\
\hline
\end{tabular}

importante, pois serviria de ponto de partida para uma definição dos objetivos que o aluno precisaria atingir para exercer bem a sua atividade futura. Esta reflexão crítica levou muitos docentes a uma mudança sobre a ênfase dada em sua disciplina, uma vez que se conscientizaram das interrelações entre o processo de ensinoaprendizagem e o desempenho do profissional na sociedade.

A partir desta reflexão, os docentes formularam os objetivos educacionais da disciplina integrada. Neste momento, muitas divergências surgiram entre os docentes das diferentes áreas. Alguns gostariam de ver sua área mais valorizada, embora muitas vezes os argumentos fossem mais afetivos do que lógicos.

A Figura 1 mostra as etapas que foram seguidas para o planejamento do curso. A primeira etapa foi elaborar a lista dos objetivos educacio- 
FIGURA 1

FLUXOGRAMA DE DESENVOLVIMENTO DOS CURSOS

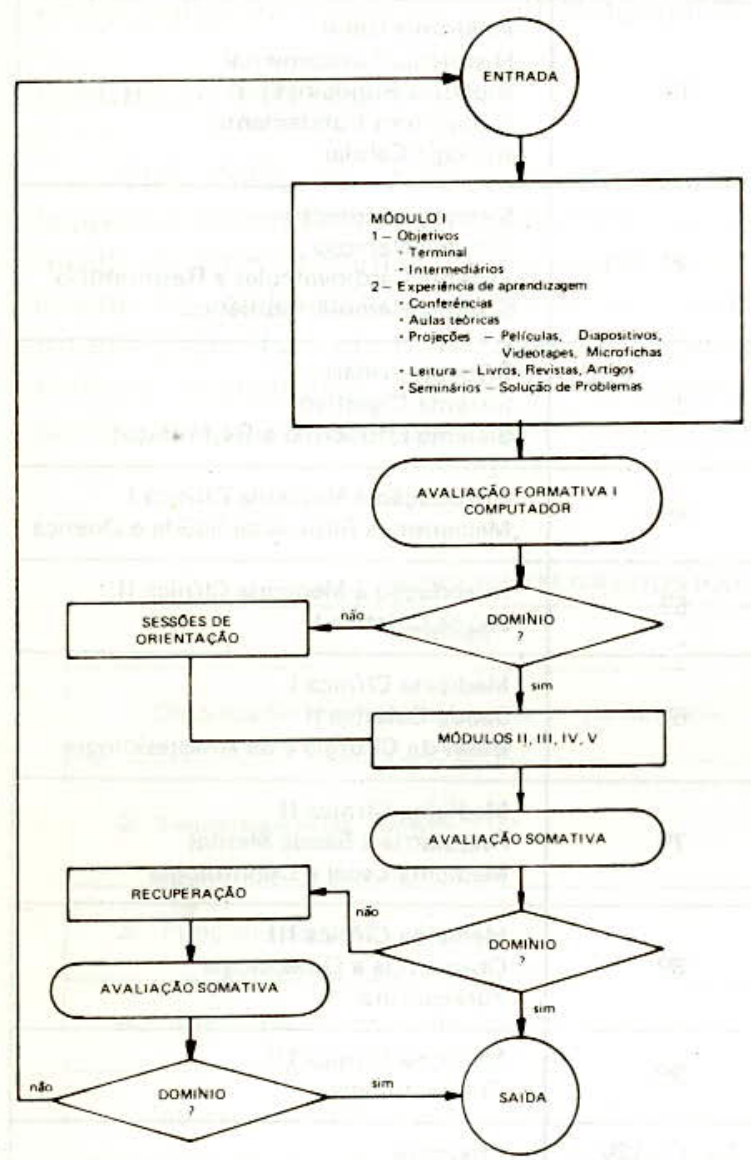

nais que se pretendia alcançar. Numa segunda etapa, os docentes procederam à escolha do conteúdo e das experiências de aprendizagem para serem postos em execução. Os conteúdos deveriam estar relacionados diretamente com os objetivos propostos, e as experiências de aprendizagem deveriam ser relevantes e diretamente relacionadas com o que se desejava ensinar. Neste momento, muitos docentes decidiam escrever o seu próprio texto básico, numa tentativa de reunir num único material a bibliografia dispersa. Este processo deu origem a um livro-texto referente ao Sistema Cardiorrespiratório ${ }^{5}$ e a um texto completo, mimeografado, sobre sistema nervoso, além de inúmeros textos avulsos em outras disciplinas.

Após a seleção dos conteúdos, procedeu-se ao planejamentc da avaliação formativa. A Figura 2 mostra os passos para a construção de ques- tões da avaliação formativa, utilizando o computador. "A avaliação formativa tem como função básica fornecer feedback aos alunos e professores sobre o processo de ensino-aprendizagem. $\mathrm{O}$ teste formativo possibilita um diagnóstico do progresso do aluno determinando se este dominou ou não a Unidade e o que deve ainda fazer para dominá-la".

FIGURA 2

\section{FLUXOGRAMA DO SISTEMA DE AVALIAÇĀO FORMATIVA}

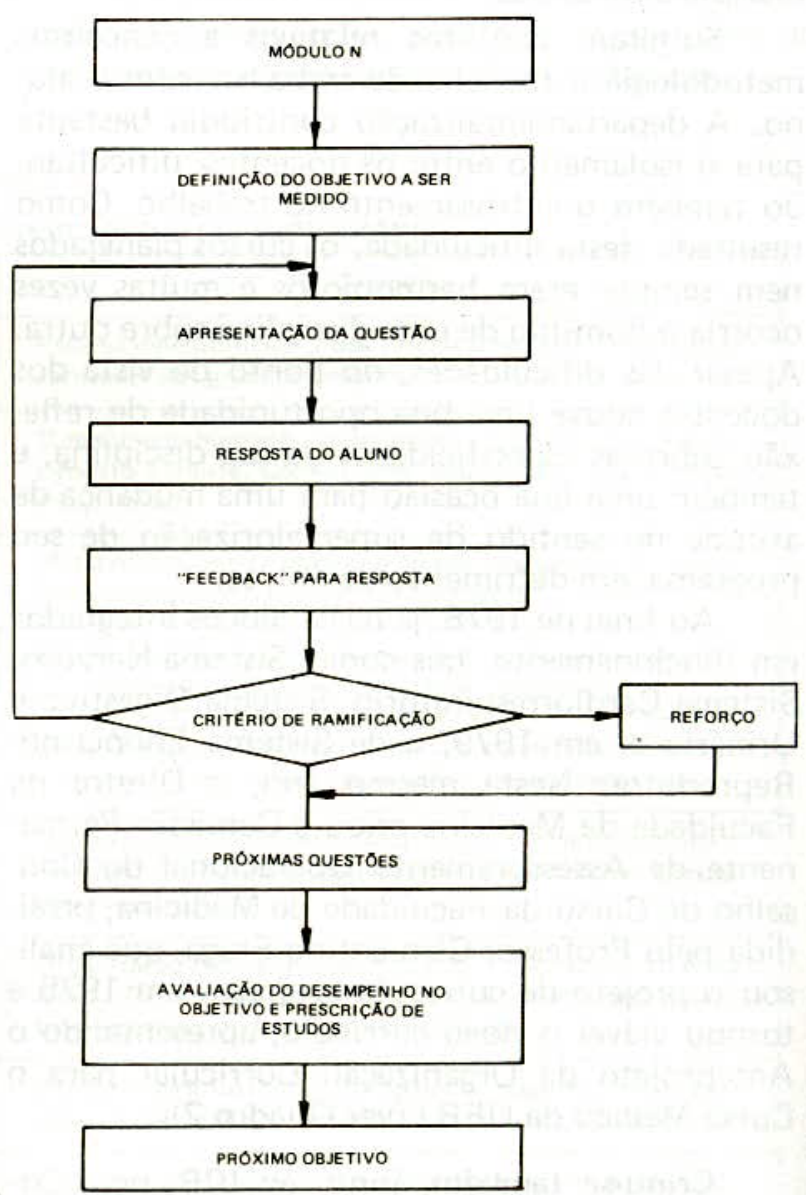

O NUTES/CLATES implantou, desde 1974, um sistema computadorizado capaz de avaliar o aluno nos diferentes blocos de ensino, através de uma linguagem que possibilita ao aluno interagir com o programa, como se estivesse em uma conversa com a máquina. $\mathrm{O}$ aluno seleciona as questões que vai responder de acordo com os objetivos da unidade. A linguagem usada é denominada MIIS (Meditech Information Interpretative System), implementada em computador DEC-PDP $15 / 75$. 
O sistema de avaliação formativa conta com um número de questões proporcionais aos objetivos educacionais da disciplina. Cada questão fornece ao aluno um feedback para as suas respostas. Os feedbacks das respostas corretas fornecem mensagens de estímulo ao aluno, enquanto os feedbacks das respostas erradas contêm pistas e informações visando levar o aluno a encontrar a resposta correta. As questões foram planejadas pelos docentes das disciplinas, que procuraram compatibilizá-las com os objetivos propostos. O quadro 3 mostra um exemplo de uma questão do Curso de Sistema Endócrino.

\section{QUADRO 3}

\section{EXEMPLO DE QUESTÃO DO SISTEMA} DE AVALIAÇĀO FORMATIVA

Curso: Sistema Endócrino

Módulo: Metabolismo Ósseo

Objetivo: 3

Questão: 24

\section{TEXTO}

A administração de paratormônio (pth) diminui a formação óssea, produzindo também diminuição do consumo de oxigênio, diminuição da captação de ácidos aminados pelos osteoblastos, diminuição da incorporação da glicina na matriz óssea.

1. Verdadeiro

2. Falso

Resposta:

"FEEDBACK" 1

Além dos efeitos indicados, o pth diminui a conversão de prolina em hidroxiprolina do colageno, e diminui também a atividade osteoblástica.

\section{"FEEDBACK" 2}

Engano seu! Na verdade, além de ter todos estes efeitos no osso, o pth ainda diminui a atividade dos osteoblastos e diminui a conversão de prolina em hidroxiprolina do colágeno.

Ao aluno, solicitava-se que comparecesse pelo menos uma vez por semana ao computador, para fazer sua avaliação formativa, relativa ao módulo estudado durante a semana. Ao final da avaliação, tanto o aluno quanto o professor recebiam um relatório relativo ao desempenho do aluno naquela avaliação. O professor também recebia um relatório do desempenho do seu grupo de alunos em cada objetivo do curso. O computador fornecia também, ao docente, a relação de comentários feitos pelos alunos ao final do programa. Cabe ressaltar que alguns cursos do ICB trabalham usando a avaliação forma- tiva, sem utilizar o computador.

Outra etapa do planejamento se referiu à seleção de meios audiovisuais a serem usados durante o ensino da disciplina, como auxiliares para o processo de ensino-aprendizagem. Os docentes poderiam criar o seu próprio material (slide-som, video-tape, tapes, cartazes) ou utilizar material já produzido anteriormente. Este, no entanto, deveria estar diretamente relacionado com os objetivos educacionais propostos.

A última etapa do planejamento foi a elaboração da avaliação somativa, ou avaliação final. Suas questões foram elaboradas a partir dos objetivos terminais do curso. Uma tabela de dupla entrada foi construída para que a porcentagem de questões finais fosse proporcional aos objetivos desenvolvidos no curso, segundo o seu nível de complexidade.

\section{IMPLEMENTAC̣ĀO DAS DISCIPLINAS INTEGRADAS}

O planejamento das disciplinas integradas era elaborado no semestre anterior; desta forma, no início do curso, todo o material já estava preparado.

Preparava-se um "Informe ao Estudante" onde os alunos encontravam, além de uma introdução, informações gerais sobre o curso, a listagem dos objetivos operacionais das diferentes disciplinas que compunham a disciplina integrada. Este informe continha ainda referências bibliográficas, o material audiovisual disponível na Biblioteca de Recursos Instrucionais, e informações sobre o funcionamento da avaliação formativa.

De acordo com a orientação da equipe do NUTES/CLATES, as aulas expositivas não eram encorajadas como constituindo um dos únicos recursos didáticos usados pelo professor. A aula expositiva era usada no início do módulo, como motivadora para os tópicos da semana. Uma conferência sobre assuntos clínicos ligados ao assunto básico do módulo também fazia parte da motivação dos alunos. Para pronunciar estas conferências eram convidados docentes do ciclo clí. nico, que procuravam estabelecer ligações entre os conhecimentos básicos e a sua utilização na clínica. As conferências tinham uma freqüência muito grande, sendo muito apreciadas. A ênfase maior, no entanto, era dada aos seminários e às sessões de orientação. 
Para as sessões de orientação, o docente recebia um grupo de alunos pelos quais seria responsável ao longo do curso (em geral quarenta alunos). Estes alunos deveriam procurar o professor-orientador para discutir dúvidas referentes ao material estudado naquele módulo específico, antes de se apresentarem para a avaliação formativa. Estas sessões eram bastante informais e o docente procurava orientar os alunos, diante de dificuldades.

Outra atividade importante do módulo era o seminário semanal com o docente. Este seminário era estruturado em torno de problemas que deveriam ser discutidos pelo grupo de alunos, e selecionado de acordo com o material estudado naquela semana. Este método, embora possibilitasse que a relação professor/aluno se tornasse mais próxima, muitas vezes criava dificuldade para alguns docentes habituados a uma relação menos pessoal com os alunos, nos anfiteatros e aulas expositivas. A perspectiva de apresentar problemas para serem solucionados pelos alunos gerou um grande interesse. Os alunos sentiam-se mais atuantes nos seminários e, conseqüentemente, retinham melhor os conceitos aprendidos. Como afirmou Lobo, "a abordagem interdisciplinar, o planejamento de atividades de ensino que ensejem ao aluno a reflexão crítica e o iniciem na estratégia de solução de problemas... são conceitos que deverão certamente nortear o planejamento de um ciclo básico melhor ajustado às necessidades da formação médica. ${ }^{\prime 3}$

Coube à equipe do NUTES/CLATES realizar, também, reuniões com os docentes, ao longo do curso, no sentido de discutir os problemas de relacionamento professor/aluno e ajudá-los a trabalhar melhor neste novo enfoque como professor-orientador. Alguns grupos de docentes chegaram, mesmo, a participar de sessões de dinâmica de grupo, coordenadas por docentes do NUTES/CLATES. As discussões sobre a relação professor/aluno levaram os docentes a se conscientizarem mais do seu papel de professor e da sua responsabilidade frente ao processo ensino/ aprendizagem.

\section{AVALIAC̣ĀO DAS DISCIPLINAS INTEGRADAS}

A avaliação do método de ensino era realizada por meio de questionários distribuídos aos alunos. Estes forneciam, através de suas críticas, informações importantes para o replanejamento. Muitas vezes, as críticas se referiam ao tempo para aprendizagem, à obrigatoriedade da avaliação formativa e ao reduzido número de audiovisuais. Na verdade, as falhas na produção de material estavam muito relacionadas ao tempo e à falta de disponibilidade de docentes e técnicos para produzir o número suficiente de material para cada curso. Críticas também foram feitas à metodologia como um todo.

Alguns alunos não gostaram de receber os objetivos do curso e acharam que o texto básico limitava o seu desenvolvimento. Por outro lado, muitos alunos apontavam como positivo o fato de receberem o planejamento do curso com a lista de objetivos educacionais, o cronograma de atividades e a bibliografia, o que Ihes proporcionava, desde o início do curso, uma visão global da disciplina. Muitos mostraram-se favoráveis à avaliação formativa computadorizada como um elemento de ajuda na aprendizagem. O material audiovisual era bastante usado pelo aluno durante os cursos.

Algumas pesquisas de avaliação do novo método de ensino foram feitas ao longo deste período. A primeira, realizada por Machado Coelho ${ }^{4}$, teve como objetivo investigar a eficiência do método de auto-instrução no rendimento dos alunos na disciplina de Fisiologia Cardiorrespiratória. A variável experimental correspondia à auto-instrução compreendendo interação ativa do aluno com o material instrucional disponível e o sistema de avaliação formativa apresentado pelo computador. Os resultados obtidos indicaram que não houve diferenças significativas entre a aprendizagem do grupo experimental e o de controle. Entretanto, revelou-se uma tendência no sentido de serem as médias maiores no grupo experimental.

Em uma assessoria a docentes, pudemos notar que, pelo menos no que se refere aos docentes de Fisiologia Cardiorrespiratória, o professor desempenha de maneira apenas fragmentária, parcial e contingente, o seu papel de orientador. Seria fundamental a discussão do papel do professor como orientador se quisermos implementar a aprendizagem e formar um profissional consciente.

O trabalho de Almeida ${ }^{1}$ procura verificar se a proposta do NUTES/CLATES apresenta todos os componentes do Modelo de Aprendizagem para o Domínio desenvolvido por Bloom ${ }^{2}$. 
Este modelo tem como pressuposto básico que todos os alunos podem aprender, desde que lhes seja dado tempo suficiente e materiais de instrução variáveis, de acordo com o estilo de aprendizagem de cada aluno. A pesquisa de Almeida mostrou que um dos procedimentos operacionais deste modelo, o sistema tutorial, representava um ponto vulnerável da proposta do NUTES/CLATES. O sistema tutorial pressupõe que cada luno deverá ter um orientador fixo durante o curso. Este sistema é largamente dependente da eficiência e da eficácia da prática didática do professor, sobre a qual a intervenção do NUTES/CLATES pode não ter sido adequada ou suficiente. De uma maneira geral, afirma a autora, pode-se dizer que o êxito de qualquer proposta pedagógica depende fundamentalmente do desempenho do professor nos vários moinentos do processo didático: planejamento, execução e avaliação do processo de ensino-aprendizagem.

Atualmente, encontra-se em andamento um projeto de pesquisa que visa a dimensionar o relacionamento entre o NUTES/CLATES e o ICB, em busca de explicações mais amplas para os êxitos e fracassos ocorridos. Está sendo desenvolvido, também, um questionário a ser enviado a uma amostra de docentes que participaram dos cursos de treinamento didático de curta duração promovidos pelo NUTES/CLATES desde 1973. $O$ total de docentes que participaram destes cursos está em torno de seis mil, abrangendo docentes do Brasil e da América Latina. Este questionário visa a avaliar o impacto desses cursos na prática destes docentes, assim como das mudanças metodológicas e curriculares que foram propostas.

\section{COMENTĀRIOS}

Embora saibamos das dificuldades que têm os docentes de trabalharem de maneira integrada, tendo em vista o seu hábito de trabalho isolado, não podemos deixar de salientar a importância deste esforço conjunto. Os problemas na área de saúde são problemas interdisciplinares. Os alunos devem, desde o ciclo básico, ser capazes de pensar e resolver problemas interdisciplinarmente. Maior integração deve ser tentada, também, entre o ciclo básico e o ciclo clínico, visando a programação de currículos mais harmonio- sos e mais próximos da realiade de atuação do futuro profissional. A integração entre o ensino e o serviço só contribuirá para o aperfeiçoamento da formação do profissional de saúde.

Devemos também estar atentos para a importância do treinamento e assessoramento didático dos docentes na área da saúde. Como demonstrou a pesquisa de Almeida, muitas falhas no processo educacional estão diretamente relacionadas ao despreparo pedagógico dos docentes. Alguns deles têm dificuldades de planejar e implementar os cursos de maneira a enfatizar o processo de aprendizagem. A ênfase ao processo educacional deve estar na aprendizagem do aluno.

O NUTES/CLATES tem contribuído para ampliar no ICB a discussão sobre a importância do planejamento curricular integrado, da utilização de uma metodologia em que o aluno seja o agente da aprendizagem com o assessoramento dos professores, da utilização de avaliações periódicas do processo de aprendizagem e da utilização correta de diferentes materiais instrucionais. Tem contribuído, também, para uma valorização das atividades de ensino. Apesar disto, muitas mudanças ainda deverão ocorrer até que possamos contar com um currículo mais adequado para a formação de profissionais conscientes do seu papel de agentes de mudanças na sociedade.

\section{SUMMARY}

This article describes the action of the NUTES/CLATES concerning the curricular plan for the basic cycle of the undergraduate course at the Federal University of Rio de Janeiro Medical School. It analyses the curricular changes as well as the used methodology in the courses. It also points out the importance of the subjects of the basic cycle which facilitates the teaching-learning process. The article stresses the importance of the pedagogic training of teachers.

\section{REFERẼNCIAS BIBLIOGRĀFICAS}

1. ALMEIDA, V. - A Utilização de Tecnologia Educacional na Universidade Federal do Rio de Janeiro: Análise de uma experiência. Pontifícia Universidade Católica, Rio de Janeiro, 1980, tese de mestrado. 
2. BLOOM, B. et alii - Handbook on Formative and Summative Evaluation of Student Learning. New York, McGraw Hill, 1971.

3. LOBO, L.C.G. - Ensino das matérias básicas. Revista Brasileira de Educação Médica, Rio de Janeiro, 5 (2): 95-8, maio/ago. 1981.

4. MACHADO COELHO, M.A.S. - A Eficiência da avaliação formativa na aprendizagem. Rio de Janeiro, Fundação Getúlio Vargas, 1975, tese de mestrado.
5. PAES DE CARVALHO, A.P.; COSTA, A. F. - Circulação e Respiração: fundamentos de Biologia e Fi. siologia. Rio de Janeiro, Universidade Federal do Rio de Janeiro, 1974.

\section{Endereço do autor: NUTES/CLATES}

Edifício Centro de Ciências da Saúde, Bloco A - S/26 IIha do Fundão

Caixa Postal 8002 - Rio de Janeiro 